\title{
Emission of volatile organic compounds from composting of different solid wastes. Abatement by biofiltration.
}

Estel.la Pagans, Xavier Font*, Antoni Sánchez

Escola Universitària Politècnica del Medi Ambient

Universitat Autònoma de Barcelona

Rbla Pompeu Fabra 1, 08100-Mollet del Vallès (Barcelona, Spain)

*Corresponding Author: Dr. Xavier Font

Escola Universitària Politècnica del Medi Ambient

Universitat Autònoma de Barcelona

Rbla Pompeu Fabra 1, 08100-Mollet del Vallès (Barcelona, Spain)

Tel.: (34) 9357967 82; Fax: (34) 935796785

E-mail: xfont@eupma.uab.es

Pre-print of: Pagans, E.; Font, X. and Sánchez, A. "Emission of volatile organic compounds from composting of different solid wastes: abatement by biofiltration" in Journal of hazardous materials (Ed. Elsevier), vol. 131, issues 1-3 (April 2006), p. 179-186. The final version is available at DOI 10.1016/j.hazmat.2005.09.017 


\begin{abstract}
Emission of volatile organic compounds (VOCs) produced during composting of different organic wastes (source-selected organic fraction of municipal solid wastes (OFMSW), raw sludge (RS) and anaerobically digested wastewater sludge (ADS) and animal by-products (AP)) and its subsequent biofiltration have been studied. Composting was performed in a laboratory scale composting plant (30 1) and the exhaust gases generated were treated by means of a compost biofilter. VOCs concentration in the composting exhaust gases for each composting process ranged from 50 to $695 \mathrm{mg} \mathrm{C} \cdot \mathrm{m}^{-3}$ for OFMSW (5:1), from 13 to $190 \mathrm{mg} \mathrm{C} \cdot \mathrm{m}^{-3}$ for OFMSW (1:1), from 200 to $965 \mathrm{mg} \mathrm{C} \cdot \mathrm{m}^{-3}$ for $\mathrm{RS}$, from 43 to $2900 \mathrm{mg} \mathrm{C} \cdot \mathrm{m}^{-3}$ for ADS and from 50 to $465 \mathrm{mg} \mathrm{C} \cdot \mathrm{m}^{-3}$ for AP. VOCs emissions were higher during the beginning of the composting process and were not generally related to the biological activity of the process. These emissions corresponded to an average loading rate applied to the biofilter from 2.56 to $29.7 \mathrm{~g} \mathrm{C} \cdot \mathrm{m}^{-3}$ biofilter $\cdot \mathrm{h}^{-1}$. VOCs concentration in the exhaust gas from the biofilter ranged from 55 to $295 \mathrm{mg} \mathrm{C} \cdot \mathrm{m}^{-3}$ for OFMSW (5:1), from 12 to 145 $\mathrm{mg} \mathrm{C} \cdot \mathrm{m}^{-3}$ for OFMSW $(1: 1)$, from 55 to $270 \mathrm{mg} \mathrm{C} \cdot \mathrm{m}^{-3}$ for $\mathrm{RS}$, from 42 to $855 \mathrm{mg} \mathrm{C} \cdot \mathrm{m}^{-}$ ${ }^{3}$ for ADS and from 55 to $315 \mathrm{mg} \mathrm{C} \cdot \mathrm{m}^{-3}$ for AP. Removal efficiencies up to $97 \%$ were achieved although they were highly dependent of the composted waste. An important observation was that the compost biofilter emitted VOCs with an estimated concentration of $50 \mathrm{mg} \mathrm{C} \cdot \mathrm{m}^{-3}$.
\end{abstract}

Key words: biofiltration, volatile organic compounds, composting, compost biofilter, organic solid wastes. 


\section{Introduction}

Denomination of volatile organic compounds (VOCs) refers to organic compounds which vapour pressure is at least $0.01 \mathrm{kPa}$ at $20^{\circ} \mathrm{C}$. VOCs are also characterised by their low water solubility. Processes involving solvents, paints or the use of chemicals are the most significant sources of VOCs, however waste and wastewater treatment facilities are also important VOCs producers. The environmental problem caused by the presence of VOCs in gaseous streams is due to the fact that many of them produce bad odours or are hazardous. For this reason VOCs are being subject to increasingly severe constrains; in Europe, for example, VOCs are controlled through the EU Directive 1999/13/EC [1] on the limitation of emissions of volatile organic compounds.

Composting is a technology widely used for the treatment of solid organic wastes. Composting allows wastes to be disposed of by reducing their size and volume. It is an extended technology for treating household wastes, but it is also applied to residuals coming from industrial activities. Municipal or industrial wastewater excess sludge [2] and animal by-products [3] are examples of organic solid wastes susceptible to be composted.

Composting exhaust gases are characterised by high flow rates and, normally, low pollutant concentration, in which VOCs can be found among the major pollutants. Van Durme [4] identified dimethyl sulphide, dimethyl disulphide, limonene and $\alpha$ pinene as the most significant odorous VOCs at a wastewater sludge composting facility. According to this work, the latter two compounds were released from wood chips used as a bulking agent. Incomplete or insufficient aeration during composting can produce sulphur compounds of intensive smell, while incomplete aerobic degradation processes also result in the emission of alcohols, ketones, esters and organic 
acids [5]. Eitzer [6] measured the highest concentration of almost all VOCs in composting plants at the early stages of the composting process.

Among the available options for the treatment of polluted air, biofiltration is an odour reduction technique that can be adapted to reduce emissions from composting processes [7]. Moreover, biofiltration is a biological technique, and is both economically and environmentally viable. It is considered a suitable technology in terms of waste recycling, filtering effect, and at the same time, reduces costs in construction and operational work [8]. In fact, biofiltration is presently used as one of the newest technologies for odour abatement in composting facilities $[9,10]$.

In a biofilter, a contaminated/odorous gas stream passes through a biologically enriched layer of a filter material followed by a biodegradation of the absorbed/adsorbed pollutants. The by-products of microbial oxidation are primary water, carbon dioxide, mineral salts, some volatile organic compounds and microbial biomass [11]. The performance of a biofilter is not uniform and it is influenced by several important variables. Microbial activity is affected by moisture content, $\mathrm{pH}$, nutrient limitation, temperature and microbiology of the biofilter medium [12].

In recent years, a large number of studies have been conducted on VOC biofiltration with several support materials (compost, pine bark, wood chips, peat, inorganic supports or mixed materials) and some hydrophobic and hydrophilic compounds found in different industries [13-16]. Elimination capacities for benzene, toluene and xylene of $60 \mathrm{~g} \mathrm{C} \cdot \mathrm{m}^{-3}$ biofilter $\cdot \mathrm{h}^{-1}$ with a removal efficiency of $75 \%$ [17] and $18 \mathrm{~g} \mathrm{C} \cdot \mathrm{m}^{-3}$ biofilter $\cdot \mathrm{h}^{-1}$ with a removal efficiency of $81 \%$ [18] have been reported using organic materials and compost respectively. However, these studies on biofiltration take only in account the presence of a couple or even a single compound, which is not the 
normal situation in composting plants, where the composted wastes are variable and heterogeneous.

This work studies VOCs emissions generated during the composting of different organic residues such as source-selected organic fraction of municipal solid wastes (OFMSW), raw sludge (RS), anaerobically digested sludge (ADS) and animal byproducts (AP). The abatement of the VOCs generated during the waste composting using the biofiltration technology is also presented.

\section{Materials and Methods}

\subsection{Organic wastes composted}

OFMSW was obtained from the municipal composting plant of Jorba (Barcelona, Spain); ADS was obtained from the urban wastewater treatment plant of La Llagosta (Barcelona, Spain); RS was obtained from the urban wastewater treatment plant of La Garriga (Barcelona, Spain); and AP, consisting of rejected parts of chicken and rabbit (viscera, carcasses, feathers, etc.), were obtained from the municipal composting plant of Jorba (Barcelona, Spain). All wastes were manually mixed with bulking agents (chopped pruning waste) to ensure an optimal porosity and moisture content. In the case of OFMSW two volumetric ratios of bulking agent:waste (5:1, 1:1) were tested. A volumetric ratio of bulking agent:waste of 1:1 was used for RS and ADS, which was previously found as optimal for sludge composting at laboratory scale [19], and 3:1 for AP, as this is the usual ratio used in the composting plant. The most important parameters of each waste are presented in Table 1. 


\subsection{Experimental set-up}

OFMSW, RS, ADS and AP were composted in this order in a thermally insulated 301 laboratory reactor. Air was supplied to the reactor intermittently by a suction-type blower (Sensotran, Spain, model GCYA/BA) to control the content of oxygen (Sensotran, Spain, model Sensox 6C) in the composting material to ensure aerobic conditions (oxygen concentration above 10\%). The blower extracted the air (5 $1 \cdot \min ^{-1}$ ) through the compost mass and discharged the exhaust gas to a pilot-scale biofilter filled with mature compost as a biofilter medium (Table 2). Each biofiltration run was performed with the same packing material, as this is the normal operation in a composting plant.

Down-flow direction was selected to improve moisture control in the biofilter and to prevent drying of the material. Since temperature of off-gases from the composting reactor was below $35^{\circ} \mathrm{C}$, it was not necessary to cool down the gas entering the biofilter and thus, it was operated within a mesophilic temperature range throughout the whole experimental period. A scheme of the composting and biofiltration system is shown in Figure 1.

The biofilter was constructed with circular methacrylate pipe, and its dimensions were: height $1.2 \mathrm{~m}$ and diameter $0.2 \mathrm{~m}$. The media depth was $0.23 \mathrm{~m}$, resulting in a total bed volume of 7.21 , a volumetric loading rate of $41.41 \cdot 1 \mathrm{media}^{-1} \cdot \mathrm{h}^{-1}$ and a gas retention time of $86 \mathrm{~s}$. Initial properties of the mature compost used as biofilter medium are shown in Table 2.

Temperatures of the composting materials were monitored during the composting period with a Pt100 probe (Desin, Spain, model SR-NOH). All values were displayed and recorded with a personal computer every 30 minutes using a commercial data logger (Desin, Spain, DAS-8000). 
Periodic measures of temperature and pressure drop across the medium were carried out manually using a digital thermometer (Hanna, mod. Checktemp) and a Utype water manometer. Moisture of the biofilter media was also periodically measured and maintained over $45 \%$ during all the experiments.

Two runs were conducted for each waste composted, and each run lasted about 1 week. Experiments were carried out continuously for about 2 months. Values of parameters presented in this paper are calculated including all the experiments carried out. In Figures 2-6 only one replication for each waste is shown.

\subsection{Analytical methods}

The quantification of volatile organic compounds was obtained by direct injection of $250 \mu \mathrm{l}$ of sample in a gas chromatograph (Perkin Elmer Autosystem XL), equipped with a flame ionisation detector (FID) and a HP-Innowax (Agilent Technologies) capillary column (30m x $0.25 \mathrm{~mm} \times 0.25 \mu \mathrm{m}$, poliethylenglycol stationary phase). Column temperature was initially $50^{\circ} \mathrm{C}$ maintained for 2 minutes, and then increased to $200^{\circ} \mathrm{C}$ at $45^{\circ} \mathrm{C} / \mathrm{min}$, and maintained for 6 minutes. Injector and detector temperatures were $200^{\circ} \mathrm{C}$ and $250^{\circ} \mathrm{C}$ respectively. Samples were obtained using a syringe and immediately injected into the chromatograph. Sampling points are shown in Figure 1. Each data point, for both inlet and outlet concentrations, represents the average of three sequential samples collected during a period of 90 minutes. N-hexane (Scharlau, $99.9 \%$ purity) was used to quantify the VOCs concentration in $\mathrm{mg} \mathrm{C} \cdot \mathrm{m}^{-3}$ [20]. Calibration curve was obtained by injecting different amounts of liquid $n$-hexane in a sealed Tedlar bag of known volume and analysing the gas sample [14]. Quantification of total VOCs concentration was based on total peak area [20]. A 
triplicate analysis was performed for each VOC concentration and the associated error to the method was below $10 \%$.

Physico-chemical properties of the biofilter compost media and wastes composted were analysed before and after the biofiltration process for the determination of moisture content (MC), organic matter content (OM), Kjeldahl nitrogen and $\mathrm{NH}_{4}{ }^{+}-\mathrm{N}$ content, carbon/nitrogen ratio $(\mathrm{C} / \mathrm{N}), \mathrm{pH}$, electrical conductivity, and biological activity measured as respirometric index (RI), which measures the rate of oxygen consumption of the biomass and is usually conducted to determine compost stability [2]. These parameters were analyzed according to accepted methods [21].

\section{Results and Discussion}

\subsection{VOCs emitted during composting}

Composting experiments were performed for a period of two months.

Temperature profiles for each composting experiment are presented in Figures 2-6. Temperature has been used as the most important indicator of the composting process performance. According to Stentiford [22], a maximum temperature of 55 to $65^{\circ} \mathrm{C}$ is necessary to destroy pathogen microorganisms, but temperatures of 45 to $55^{\circ} \mathrm{C}$ must be maintained for maximum biodegradation. Temperature of the four wastes rose rapidly and reached the thermophilic range within one and two days. The maximum temperature achieved for OFMSW (5:1), OFMSW (1:1), RS, ADS and AP were $52.2^{\circ} \mathrm{C}$, $58.0^{\circ} \mathrm{C}, 60.0^{\circ} \mathrm{C}, 61.2^{\circ} \mathrm{C}$ and $66.2^{\circ} \mathrm{C}$, respectively.

VOCs concentration in the composting exhaust gases along each composting process ranged from 50 to $695 \mathrm{mg} \mathrm{C} \cdot \mathrm{m}^{-3}$ for OFMSW (5:1), from 13 to $190 \mathrm{mg} \mathrm{C} \cdot \mathrm{m}^{-3}$ for OFMSW (1:1), from 200 to $965 \mathrm{mg} \mathrm{C} \cdot \mathrm{m}^{-3}$ for RS, from 43 to $2900 \mathrm{mg} \mathrm{C} \cdot \mathrm{m}^{-3}$ for ADS and from 50 to $465 \mathrm{mg} \mathrm{C} \cdot \mathrm{m}^{-3}$ for AP. Average values are shown in Table 3 . As it 
can be observed, VOCs emissions in composting were highly dependent on the waste to be composted. Also, the biofilter loading rate ranged from an average values of $2.56 \mathrm{~g}$ $\mathrm{C} \cdot \mathrm{m}^{-3}$ biofilter $\cdot \mathrm{h}^{-1}$ to $29.7 \mathrm{~g} \mathrm{C} \cdot \mathrm{m}^{-3}$ biofilter $\cdot \mathrm{h}^{-1}$ for OFMSW (1:1) and ADS respectively.

As it can be seen in Table 3, there is a significant difference between VOCs concentration emitted by OFMSW (5:1) and OFMSW (1:1) composting. This is of special interest since the only difference between the two composting processes was the amount of bulking agent used. In both cases the maximum VOCs concentration was achieved in the initial $20 \mathrm{~h}$ (Figures 2 and 3). Since the temperature profile was similar in both processes, the higher emission of VOCs for OFMSW (5:1) can be attributed to the higher content of bulking agent (chopped pruning waste). Some authors $[4,10,23,24]$ have found that terpenes are primarily released from the biodegradable vegetable material used as a bulking agent in composting facilities. Therefore, it can be concluded that a high bulking agent ratio provokes a high VOCs emission.

VOCs emissions are also different when comparing RS and ADS (Table 3). Since in both cases a similar temperature profile was observed (Figures 4 and 5) and the bulking agent ratio was identical (1:1), sludges can be compared in terms of VOCs emissions. Results obtained indicate high concentration of VOCs emitted during ADS than RS composting (average value of $715 \mathrm{mg} \mathrm{C} \cdot \mathrm{m}^{-3}$ and $550 \mathrm{mg} \mathrm{C} \cdot \mathrm{m}^{-3}$ for ADS and RS respectively). According to Van Durme [4], VOCs emissions during composting of raw sludge are greater or equal to VOCs emitted during digested sludge composting. However, in our case, higher VOCs concentration was detected for ADS composting. Probably, other factors such as anaerobic digestion efficiency or sludge characteristics may affect VOCs emissions in waste sludge composting. In both cases, the maximum VOCs concentration was achieved in the initial $20 \mathrm{~h}$. However, whereas RS VOCs concentration was maintained around $700 \mathrm{mg} \mathrm{C} \cdot \mathrm{m}^{-3}$ within the initial $90 \mathrm{~h}$, ADS 
composting VOCs concentration clearly decreased from 3000 to $170 \mathrm{mg} \mathrm{C} \cdot \mathrm{m}^{-3}$. The causes of these results are not clear, we can either hypothesise that ADS might contain a low amount of VOCs (as the content of organic matter is expected to be low) or that VOCs might be released during the first stage of composting.

Finally, for AP composting (Figure 6), two peaks of VOCs emission were detected, one at the beginning of the composting process and a second one after $70 \mathrm{~h}$ of process time. It should be noted that high temperatures in AP composting were maintained for a longer period and this fact may be the cause of a sustained VOCs emission.

Temperature in a composting process is an indicator of biological activity [25]. For this reason a longer thermophilic period (temperature above $45^{\circ} \mathrm{C}$ ) implies high biological activity. It is interesting to note that VOCs emitted in the composting of the five wastes investigated do not reveal a dependence on biological activity. According to temperature profile, AP is the waste with the highest activity, followed by RS, OFMSW (1:1), ADS and OFMSW (5:1). However, VOCs concentration emitted during composting of AP were lower than those emitted when composting OFMSW (5:1), ADS or RS. This is an important result since the dependence of emissions of other gases, such as ammonia, with temperature and biological activity has been shown [26].

For each composted waste the VOCs maximum production was obtained in the first $48 \mathrm{~h}$. The composting process can be divided in three stages: rising to $45^{\circ} \mathrm{C}$, above $45^{\circ} \mathrm{C}$ (thermophilic range) and decreasing from $45^{\circ} \mathrm{C}$ to ambient temperature. Maximum VOCs emissions were detected in the first or second stage (Table 4), but always during the first $48 \mathrm{~h}$. There was no coincidence between maximum VOCs emission and maximum process temperature, which is the period of maximum activity. These results agree with several studies showing that emission of volatile compounds already starts 
upon arrival of the fresh biowaste to the composting plant [27]. According to Eitzer [6], most of the volatile organic compounds in aerobic composting plants are emitted at early stages of processing, i.e. in the tipping floors where the wastes are discharged, in the shredder, and in the initial active composting area where the temperature increases to $55^{\circ} \mathrm{C}$. It was also observed a decreasing concentration of almost all VOCs from fresh to partially composted material and to cured compost. Other authors [23] found that VOCs emissions during composting of organic fraction of municipal solid wastes decreased along the thermophilic range of temperatures.

\subsection{Biofiltration of composting exhaust gases}

Exhaust gases produced during different composting processes were treated using a compost biofilter. Biofiltration media was characterised before and after the whole period. Properties of the compost media after filtering operation are shown in Table 2. The OM decreased as the effluent gas from the composting reactor was biofiltered, while the $\mathrm{MC}$ and $\mathrm{NH}_{4}{ }^{+}-\mathrm{N}$ increased because of the absorption of moisture and ammonia present in the exhaust gas. In the case of moisture, biofilter watering was not necessary as it is reported in other works [25], in which the water-saturated composting exhaust gases are biofiltered. The $\mathrm{NH}_{4}{ }^{+}-\mathrm{N}$ increase was also observed in similar experiments where biofilter ammonia loading rate ranged from 0.85 to $67.10 \mathrm{~g}$ $\mathrm{NH}_{3} \cdot \mathrm{m}^{-3}$ biofilter $\cdot \mathrm{h}^{-1}$ [28]. The value of $\mathrm{pH}$ and electrical conductivity did not change significantly. The biological activity of the compost (measured as RI) slightly increased throughout the biofiltration process probably due to a compost reactivation or to the formation of new active biological colonies. This can provoke a simultaneous degradation of the biofilter organic media as it is observed in the decrease of its organic matter content (Table 2). 
During the course of the experiments, the biofilter operated at a temperature range from 15 to $26^{\circ} \mathrm{C}$ and the pressure drop exhibited an increase of $17 \mathrm{~mm} \mathrm{H}_{2} \mathrm{O}$ due to the gradual compaction of the packing material. However, the value of the pressure drop did not increase to a critical value during the whole experimental period and no channelling phenomena were visually observed.

VOCs concentration of the exhaust gas from biofilter ranged from 55 to $295 \mathrm{mg}$ $\mathrm{C} \cdot \mathrm{m}^{-3}$ for OFMSW (5:1), from 12 to $145 \mathrm{mg} \mathrm{C} \cdot \mathrm{m}^{-3}$ for OFMSW (1:1), from 55 to 270 $\mathrm{mg} \mathrm{C} \cdot \mathrm{m}^{-3}$ for $\mathrm{RS}$, from 42 to $855 \mathrm{mg} \mathrm{C} \cdot \mathrm{m}^{-3}$ for ADS and from 55 to $315 \mathrm{mg} \mathrm{C} \cdot \mathrm{m}^{-3}$ for AP. Average values are shown in Table 3.

Figures 2-6 describe VOCs concentration in the inlet (composting exhaust gas) and outlet gas stream of biofilter, as well as the resulting removal efficiencies for the five wastes composted. As it can be observed, higher VOCs reductions were obtained during the initial stages of the composting processes, when VOCs emissions reached its maximum value.

Although removal efficiencies above $90 \%$ were reached, there were periods in which lower removal efficiencies were obtained. In relation to removal efficiencies, it can be observed that on one hand, poor removal efficiencies were obtained at the final period of the composting processes, when the lowest VOCs emission concentrations were detected. This inefficiency can be due to the fact that the biofilter emitted VOCs by itself. Nicolai and Janni [11] also observed that some VOCs can be produced as byproducts of microbial oxidation in biofilters. It was found that at the end of the whole biofiltration period, the compost biofilter released about $50 \mathrm{mg} \mathrm{C} \cdot \mathrm{m}^{-3}$, as a constant VOCs emission concentration measured during 15 days. This emission level is similar to the VOCs production measured at the final stage of composting processes. This fact must be considered when analyzing the performance of VOC biofilters (calculation of 
operational and design parameters), especially in the case where complex gas samples are treated. On the other hand, during certain periods the biofilter clearly was not able to remove all the VOCs produced during the composting process (i.e. composting AP at 70 h process time, Figure 6). In this case, low removal efficiencies should be related to the complexity of VOCs mixture emitted and their variability throughout the composting process, affecting their elimination in the biofilter. Removal efficiency reductions were observed by Kim [29] after interchanging the feed VOCs to the biofilter. According to this work, it is commonly observed that microorganisms exposed to a new substrate may require a period of acclimation before they begin vital degradation. This fact is of special interest in the design and operation of compost biofilters for treating exhaust gases in composting plants where different wastes are treated.

The influence of loading rate on elimination capacity and the calculation of the critical loading rate is shown in Figure 7. The solid line indicates the total elimination of inlet VOCs, whereas experimental data are indicated by symbols. For the calculation of the critical loading rate, experimental points were determined considering the VOCs emissions from biofilter itself and assuming that they were constant with a value of 50 $\mathrm{mg} \mathrm{C} \cdot \mathrm{m}^{-3}$. Efficiencies obtained were highly dependent of the waste composted and of the type of VOCs emitted during composting. VOCs emitted during OFMSW (1:1) composting were removed with efficiencies above $90 \%$ for loading rates up to $5 \mathrm{~g} \mathrm{C} \cdot \mathrm{m}^{-3}$ biofilter $\cdot \mathrm{h}^{-1}$. However, for OFMSW (5:1) at the same loading rate, only efficiencies up to $80 \%$ were obtained, indicating that VOCs emitted were more recalcitrant to degradation. For VOCs emitted during biofiltration of RS, efficiencies above $88 \%$ were obtained for loading rates up to $34.0 \mathrm{~g} \mathrm{C} \cdot \mathrm{m}^{-3}$ biofilter $\cdot \mathrm{h}^{-1}$. However, for ADS exhaust gases biofiltration at loading rates up to $34.0 \mathrm{~g} \mathrm{C} \cdot \mathrm{m}^{-3}$ biofilter $\cdot \mathrm{h}^{-1}$ efficiencies lower than $80 \%$ were obtained. This fact can again indicate that the composition of VOCs mixture 
obtained during the composting of each organic waste has a dramatic effect on the performance of the biofilter. Finally, efficiencies achieved in the biofiltration of exhaust gases from AP composting were generally lower than $30 \%$ except from the first points. It is probable that this low efficiency is due to the low inlet VOCs concentration or a lack of acclimation of microorganisms.

Deshusses and Johnson [30] observed that most of biofilters reached a maximum elimination capacity below $50 \mathrm{~g} \mathrm{C} \cdot \mathrm{m}^{-3}$ biofilter $\cdot \mathrm{h}^{-1}$. In a similar study, a maximum elimination capacity of $75 \mathrm{~g} \mathrm{C} \cdot \mathrm{m}^{-3}$ biofilter $\cdot \mathrm{h}^{-1}$ was determined by Aizpuru [31], treating an artificial complex VOCs mixture. The compost biofilter studied in this work obtained a maximum elimination capacity of $119.5 \mathrm{~g} \mathrm{C} \cdot \mathrm{m}^{-3}$ biofilter $\cdot \mathrm{h}^{-1}$ at a loading rate of $120.8 \mathrm{~g} \mathrm{C} \cdot \mathrm{m}^{-3}$ biofilter $\cdot \mathrm{h}^{-1}$ (Figure 7$)$. However, this value can not be defined as a real maximum elimination capacity for this biofilter. This is due to the fact that elimination capacity is highly dependent on the biofiltered VOCs, which are related to the composted waste and the composting stage.

More research is needed to determine the effect on the biofiltration process when treating complex and variable VOCs coming from different composting processes. Acclimation of microorganisms to variable air streams (in composition and concentration) should be the objective of future works on this field.

\section{Conclusions}

A compost biofilter was operated during two months treating real gases from a laboratory scale composting plant. The overall conclusions from the obtained data can be summarized as: 
1) Biofiltration of VOCs from exhaust gases of composting processes can be performed achieving different efficiencies depending on the waste composted. More sustained removal efficiencies were obtained in the composting of RS.

2) Significant differences on biofiltration of OFMSW (1:1) and (5:1) were detected. The best results were obtained in the biofiltration of exhaust gases from OFMSW (1:1) composting. This may indicate that the ratio bulking agent:waste affects the VOCs emitted during the composting process and their elimination in the biofilter. The ratio bulking agent:waste should be an important parameter to control VOCs emissions for OFMSW. This parameter will permit to reduce VOCs emissions to be treated in the biofiltration process.

3) Compost biofilters are emitters of VOCs themselves. Approximately basal emission of $50 \mathrm{mg} \mathrm{C} \cdot \mathrm{m}^{-3}$ was measured. This fact must be taken into account when calculating the removal efficiency of a biofilter treating complex samples of VOCs, and to evaluate the overall performance of the biofilter.

4) The highest concentrations of VOCs in the exhaust gases of composting processes were detected during the first $48 \mathrm{~h}$ of process time. VOCs emission during composting is not generally related to the biological activity of the process. The maximum VOCs concentration emission did not coincide with the maximum temperature achieved during composting.

5) Future research lines in this field should be focused on the identification and quantification of single VOCs and the differences found in the VOCs profile from different wastes and composting stages. 


\section{Acknowledgements}

The authors wish to acknowledge the financial support from Ministerio de Ciencia y Tecnología of the Spanish Government (Project REN2003-00823). 


\section{References}

[1] Directive 1999/13/CE relative to the reduction of Volatile Organic Compounds due to the use of organic solvents in some activities and plants, Official Journal of European Communities, n85, 1999, March 29th, Brussels, Belgium.

[2] T. Gea, R. Barrena, A. Artola, A. Sánchez, Monitoring the biological activity of the composting process: Oxygen Uptake Rate (OUR), Respirometric Index (RI), and Respiratory Quotient (RQ), Biotechnol. Bioeng. 88 (2004) 520-527.

[3] European Compost Network, Memorandum including the key messages following the ABP workshop in Maastricht, in: ECN (Eds.), Proceedings of The Animal ByProducts Regulation ABP - Impacts and Needs for Composting and Biogas Plants in Europe, Maastricht, 9-10 October 2003.

[4] G.P. Van Durme, B.F. McNamara, C.M. McGinley, Bench-scale removal of odor and volatile organic compounds at a composting facility, Wat. Environ. Res. 64 (1992) 19-27.

[5] W.J. Homas, K. Fischer, A composting plant as an odour source, compost as an adour killer, Acta Horticulturae 302 (1992) 37-44.

[6] B.D. Eitzer, Emissions of volatile organic chemicals from municipal solid waste composting facilities, Environ. Sci. Technol. 29 (1995) 896-902.

[7] J.H. Hong, K.J. Park, Wood chip biofilter performance of ammonia gas from composting manure, Compost Sci. Util. 12 (2004) 25-30.

[8] M.E. Lang, R.A. Lager, Odor control for municipal sludge composting, Biocycle 33 (1992) 76-85.

[9] S. Barrios, R. Fernández, F. Vázquez, X. Font, Composting Activity in Catalonia, Biocycle 45 (2004) 64-66. 
[10] S. Sironi, D. Botta, Biofilter efficiency in odor abatement at composting plants, Compost Sci. Util. 9 (2001) 149-155.

[11] R.E. Nicolai, K.A. Janni, Biofilter media mixture ratio of wood chips and compost treating swine odors, Wat. Sci. Technol. 44 (2001) 261-267.

[12] J.S. Devinny, M.A. Deshusses, T.S. Webster, Biofiltration for Air Pollution Control, Lewis Publication, Boca Raton, Florida, 1999.

[13] R.J. Abumaizer, W. Kocher, E.H. Smith, Biofiltration of BTEX contaminated air streams using compost activated carbon filter media, J. Hazard Mater. 60 (1998) 111-126.

[14] A. Torkian, R. Dehghanzadeh, M. Hakimjavadi, Biodegradation of aromatic hydrocarbons in a compost biofilter, J. Chem. Technol. Biotechnol. 78 (2003) 795801.

[15] A. Aizpuru, L. Malhautier, J.C. Roux, J.L. Fanlo, Biofiltration of a mixture of volatile organic compounds on granular activated carbon, Biotechnol. Bioeng. 83 (2003) 479-488.

[16] I. Ortiz, S. Revah, R. Auria, Effects of packing material on the biofiltration of benzene, toluene and xylene vapours, Environ. Technol. 24 (2002) 265-275.

[17] L. Seed, R.L. Corsi, Biofiltration of benzene, toluene, and o-xylene: substrate effects and carbon balancing, in: AWMA (Eds.), Proceedings of the 89th Annual Meeting and Exhibition of the Air and Waste Management Association, Nashville, Tennessee, 1996, 96-WP87A.06.

[18] D. Thomson, L. Sterne, J. Bell, W. Parker, A. Lye, Pilot scale investigation on sustainable BTEX removal with a composter biofilter, in: AWMA (Eds.), Proceedings of the 89th Annual Meeting and Exhibition of the Air and Waste Management Association, Nashville, Tennessee, 1996, 96-WP87A.02. 
[19] T. Gea, A. Artola, A. Sánchez, Application of experimental design technique to the optimization of bench scale composting conditions of municipal raw sludge, Compost Sci. Util. 11 (2003) 321-329.

[20] G. Spigno, C. Pagella, M.D. Fumi, R. Molteni, D. Marco De Faveri, VOCs removal from waste gases: gas-phase bioreactor for abetment of hexane by Aspergillus niger, Chem. Eng. Sci. 58 (2003) 739-746.

[21] U.S. Department of Agriculture and U.S. Composting Council, Test methods for the examination of composting and compost, Edaphos International, Houston, Texas, 2001.

[22] E.I. Stentiford, D.D. Mara, P.L. Taylor, Forced aereation co-composting of domestic refuse and sewage sludge in static piles, in: J.K.R. Gasser (Eds.), Composting of agricultural and other wastes, Elsevier Applied Science Publishers, London, 1998, pp. 42-55.

[23] D.P. Komilis, R.K. Ham, J.K. Park, Emission of volatile organic compounds during composting of municipal solid wastes, Wat. Res. 38 (2004) 707-1714.

[24] N. Defoer, I.D. Bo, H. Van Langenhove, J. Dewulf, T. Van Elst, Gas chromatography-mass spectrometry as a tool for estimating odour concentrations of biofilter effluents at aerobic composting and rendering plants, J. Chromatogr. A. 970 (2002) 259-273.

[25] R.T. Haug, The Practical Handbook of Compost Engineering, Lewis Publishers, Boca Raton, Florida, 1993.

[26] E. Pagans, X. Font, A. Sánchez, Ammonia emissions from the composting of different organic wastes dependency on process temperature, Chemosphere, in press. 
[27] E. Smet, H. Van Langenhove, I.D. Bo, The emission of volatile compounds during the aerobic and the combined anaerobic/aerobic composting biowaste, Atmos. Environ. 33 (1999) 1295-1303.

[28] E. Pagans, X. Font, A. Sánchez, Biofiltration for ammonia removal from composting exhaust gases, Chem. Eng. J., in press.

[29] D. Kim, Z. Cai, G.A. Sorial, Impact of interchanging VOCs on the performance of trickle-bed air biofilter, in: J.S. Devinny (Ed.), Proceedings of the 2004 Conference on biofiltration for air pollution control, Redondo Beach, California, 19-22 October 2004, pp. 35-41.

[30] M.A. Deshusses, C.T. Johnson, G. Leson, Treating high loads of ethyl acetate and toluene in a biofilter, in: AWMA (Eds.), Proceedings of the 90th Annual Meeting and Exhibition of the Air and Waste Management Association, Toronto, Canada, 813 June 1997, 97-WA71A.07.

[31] A. Aizpuru, L. Malhautier, J.C. Roux, J.L. Fanlo, Biofiltration of a mixture of volatile organic emissions, J. Waste Manage. Assoc. 51 (2001) 1662-1670. 


\section{TABLES}

Table 1: Properties of composted wastes (wb: wet basis; db: dry basis).

\begin{tabular}{lccccc}
\hline Parameter & OFMSW & OFMSW & & & \\
& $(5: 1)$ & $(1: 1)$ & & & ADS \\
& & & & & \\
\hline Moisture content $(\% \mathrm{wb})$ & 46.1 & 46.7 & 61.8 & 62.4 & 55.0 \\
\hline Organic matter content $(\% \mathrm{db})$ & 51.5 & 67.3 & 57.7 & 52.5 & 69.1 \\
\hline $\mathrm{pH}$ & 6.9 & 6.1 & 7.1 & 7.6 & 8.0 \\
\hline Electrical conductivity $\left(\mathrm{mS} \cdot \mathrm{cm}^{-1}\right)$ & 2.7 & 3.0 & 1.8 & 2.1 & 5.6 \\
\hline
\end{tabular}


Table 2: Properties of biofilter medium before and after the biofiltration period (wb: wet basis; db: dry basis).

\begin{tabular}{lcc}
\hline Parameter & Initial & Final \\
\hline Moisture content $(\% \mathrm{wb})$ & 40.4 & 60.8 \\
\hline Organic matter content $(\% \mathrm{db})$ & 59.7 & 48.6 \\
\hline $\mathrm{pH}$ & 8.7 & 9.0 \\
\hline Electrical conductivity $\left(\mathrm{mS} \cdot \mathrm{cm}^{-1}\right)$ & 3.3 & 3.9 \\
\hline Kjeldahl-N $(\% \mathrm{db})$ & 3.5 & 3.3 \\
\hline $\mathrm{NH}_{4}{ }^{+}-\mathrm{N}(\% \mathrm{db})$ & 0.3 & 0.9 \\
\hline $\mathrm{C} / \mathrm{N}$ & 8.7 & 6.4 \\
\hline Respirometric index $\left(\mathrm{mg} \mathrm{O}_{2} \cdot \mathrm{g} \mathrm{OM}^{-1} \cdot \mathrm{h}^{-}\right.$ & 1.03 & 1.82 \\
$\left.{ }^{1}\right)$ & \\
\hline Pressure drop $(\mathrm{mm}$ of water $)$ & \\
$*$
\end{tabular}

detected 
Table 3: VOCs emissions average (before and after biofilter), average and maximum and minimum values (in parenthesis) of loading rate and elimination capacity and removal efficiency range for the five composted wastes.

\begin{tabular}{|c|c|c|c|c|c|}
\hline & $\begin{array}{r}\text { Average V } \\
(\mathrm{m})\end{array}$ & $\begin{array}{l}\text { emissions } \\
\left.\mathrm{n}^{-3}\right)\end{array}$ & $\begin{array}{c}\text { Loading } \\
\text { Rate }\end{array}$ & $\begin{array}{c}\text { Elimination } \\
\text { Capacity }\end{array}$ & Removal \\
\hline & $\begin{array}{l}\text { Before } \\
\text { biofilter }\end{array}$ & $\begin{array}{c}\text { After } \\
\text { biofilter }\end{array}$ & $\begin{array}{c}\left(\mathrm{g} \mathrm{C} \cdot \mathrm{m}^{-3}\right. \\
\left.\text { biofilter } \cdot \mathrm{h}^{-1}\right)\end{array}$ & $\begin{array}{c}\left(\mathrm{g} \mathrm{C} \cdot \mathrm{m}^{-3}\right. \\
\left.\text { biofilter } \cdot \mathrm{h}^{-1}\right)\end{array}$ & $(\%)$ \\
\hline OFMSW (5:1) & 237 & 155 & $9.83(2.10-28.8)$ & $3.52(0-16.5)$ & $0-57$ \\
\hline OFMSW (1:1) & 61.7 & 50.7 & $2.56(0.55-7.95)$ & $0.61(0-2.90)$ & $0-60$ \\
\hline $\mathrm{RS}$ & 550 & 110 & $22.9(8.20-40.0)$ & $18.3(5.84-31.9)$ & $71-91$ \\
\hline $\mathrm{ADS}$ & 716 & 192 & $29.7(1.85-120)$ & $21.7(0-117)$ & $0-97$ \\
\hline AP & 150 & 100 & $6.25(2.20-12.0)$ & $2.29(0-15.7)$ & $0-82$ \\
\hline
\end{tabular}


Table 4: VOCs emissions during the composting process.

\begin{tabular}{lccccc}
\hline \multicolumn{6}{c}{ Average VOCs concentration $\left(\mathrm{mg} \mathrm{C} \cdot \mathrm{m}^{-3}\right)$} \\
\hline Process stage & OFMSW & OFMSW & ADS & RS & AP \\
& $(5: 1)$ & $(1: 1)$ & & & \\
& 426 & 122 & 2910 & 519 & 463 \\
\hline Rising to $45^{\circ} \mathrm{C}$ & 612 & 63 & 804 & 771 & 46 \\
\hline Above $45^{\circ} \mathrm{C}$ & 229 & 76 & 111 & 197 & 56 \\
\hline Decreasing from $45^{\circ} \mathrm{C}$ & & & & & \\
\hline
\end{tabular}




\section{LEGEND TO FIGURES}

Figure 1: Scheme of the pilot scale composting and biofiltration system. 1-Composter; 2-Biofilter; 3-Air inlet; 4-Leachates outlet; 5-Temperature probe; 6-Exhaust gas from composter and inlet biofilter gas; 7-Suction type-blower; 8-Oxygen sensor; 9-VOCs sampling ports; 10-Compost media; 11-Biofilter sampling ports; 12-Manometer; 13Outlet biofilter gas; 14-Data logger and control system; 15-Personal computer.

Figure 2: VOCs emissions in inlet (solid circles) and outlet (circles) gas streams of biofilter, average removal efficiency (squares) and temperature (solid line) of composting process of source-selected organic fraction of municipal solid wastes (5:1).

Figure 3: VOCs emissions in inlet (solid circles) and outlet (circles) gas streams of biofilter, average removal efficiency (squares) and temperature (solid line) of composting process of source-selected organic fraction of municipal solid wastes (1:1).

Figure 4: VOCs emissions in inlet (solid circles) and outlet (circles) gas streams of biofilter, average removal efficiency (squares) and temperature (solid line) of composting process of raw sludge.

Figure 5: VOCs emissions in inlet (solid circles) and outlet (circles) gas streams of biofilter, average removal efficiency (squares) and temperature (solid line) of composting process of anaerobically digested wastewater sludge. 
Figure 6: VOCs emissions in inlet (solid circles) and outlet (circles) gas streams of biofilter, average removal efficiency (squares) and temperature (solid line) of composting process of animal by-products.

Figure 7: Average elimination capacity of the compost biofilter for different loading rates of VOCs during composting of source-selected organic fraction of municipal solid wastes 1:1 (solid squares) and 5:1 (solid triangles up), raw sludge (circles), digested wastewater sludge (triangles down) and animal by-products (cross). In-box graphic corresponds to a scale enlargement. 
Figure 1: Pagans et al.

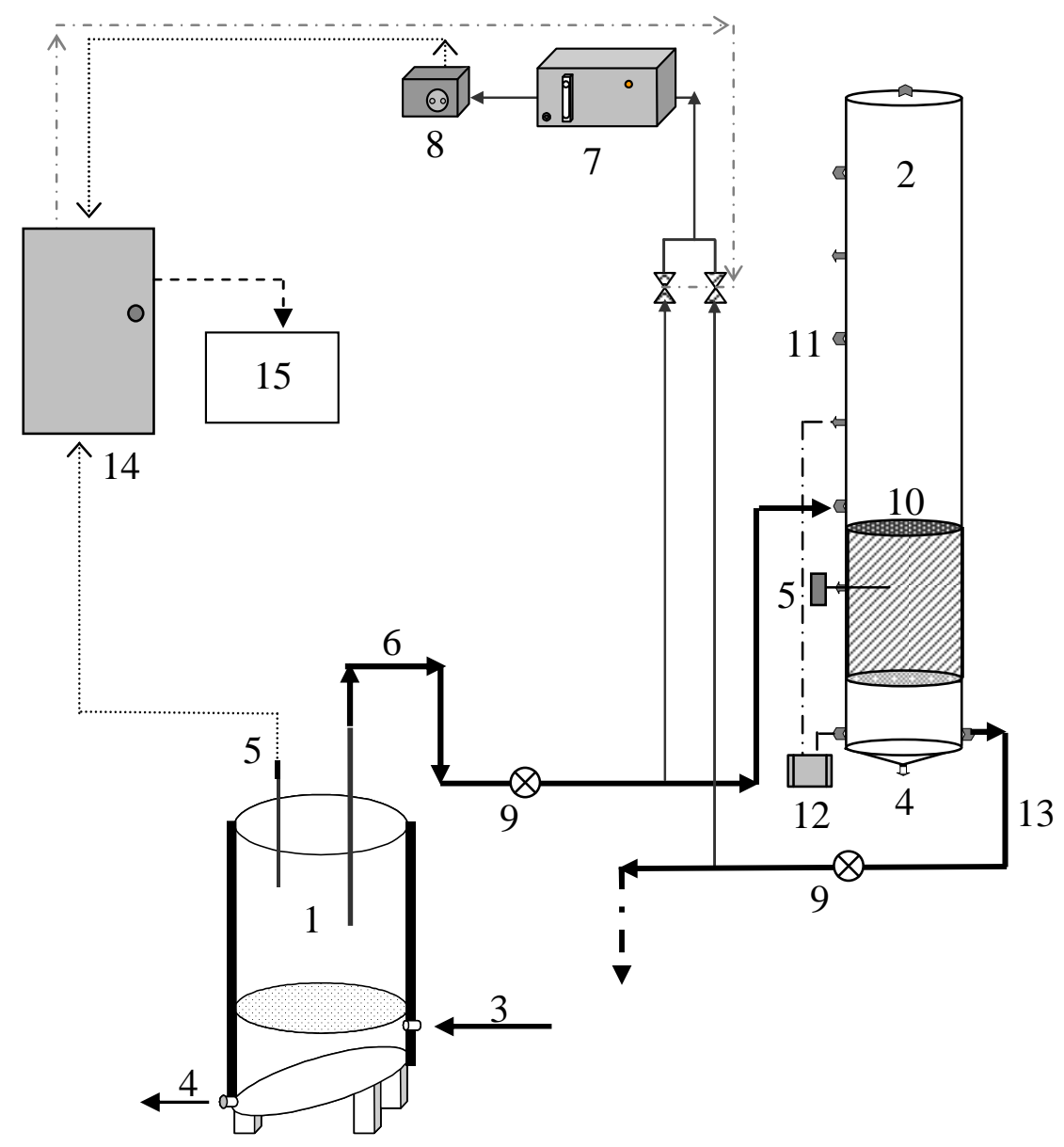


Figure 2: Pagans et al.

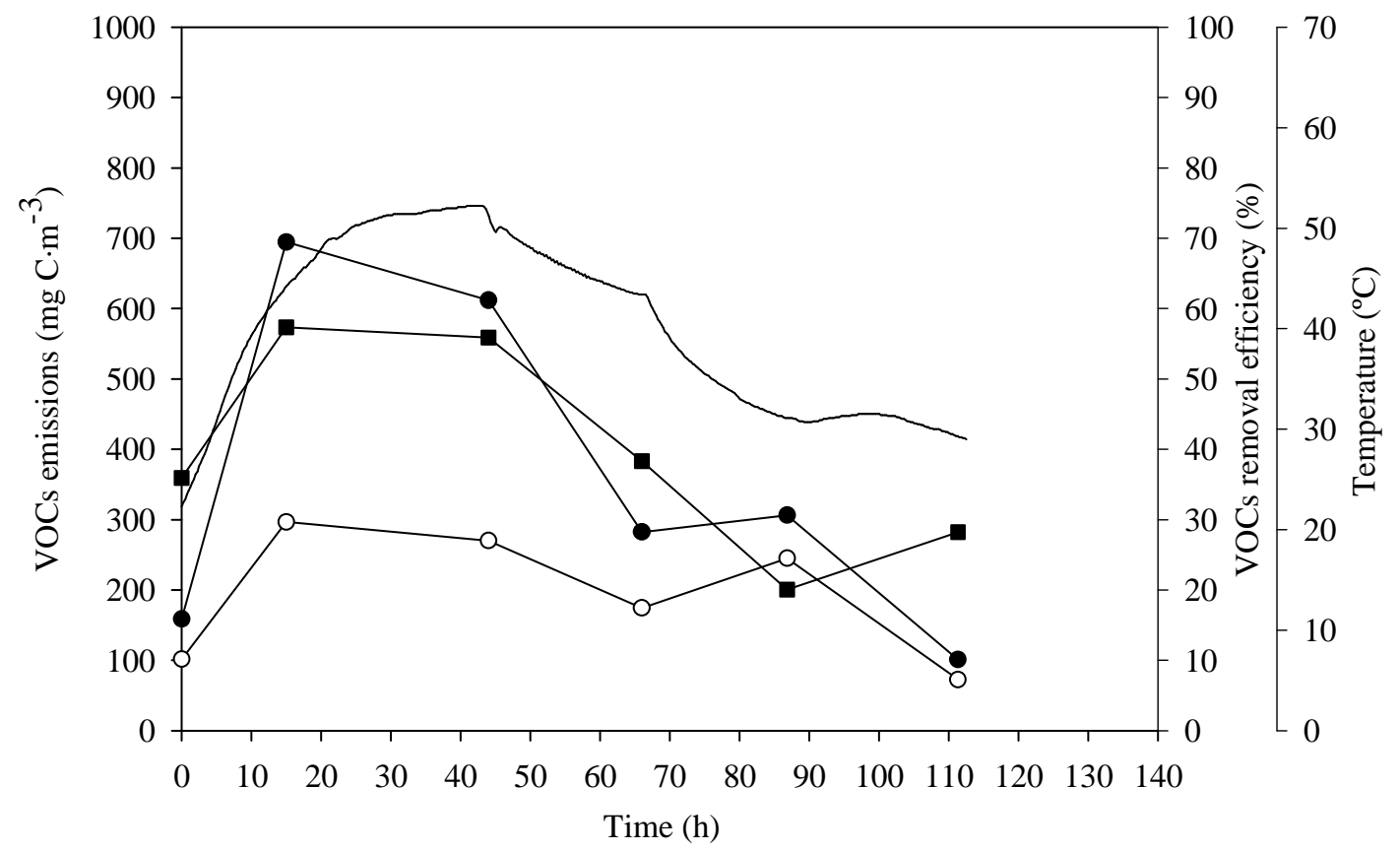


Figure 3: Pagans et al.

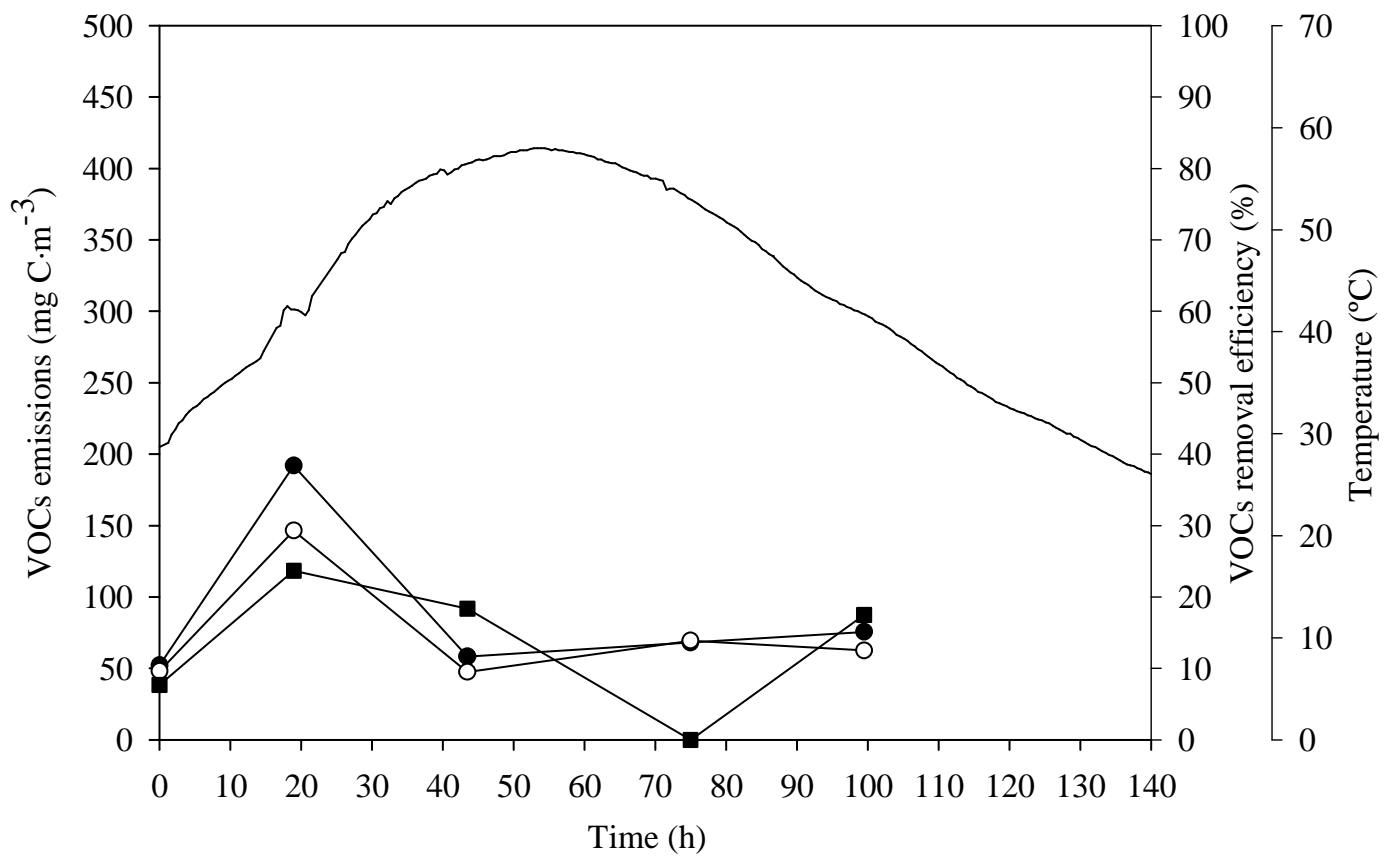


Figure 4: Pagans et al.

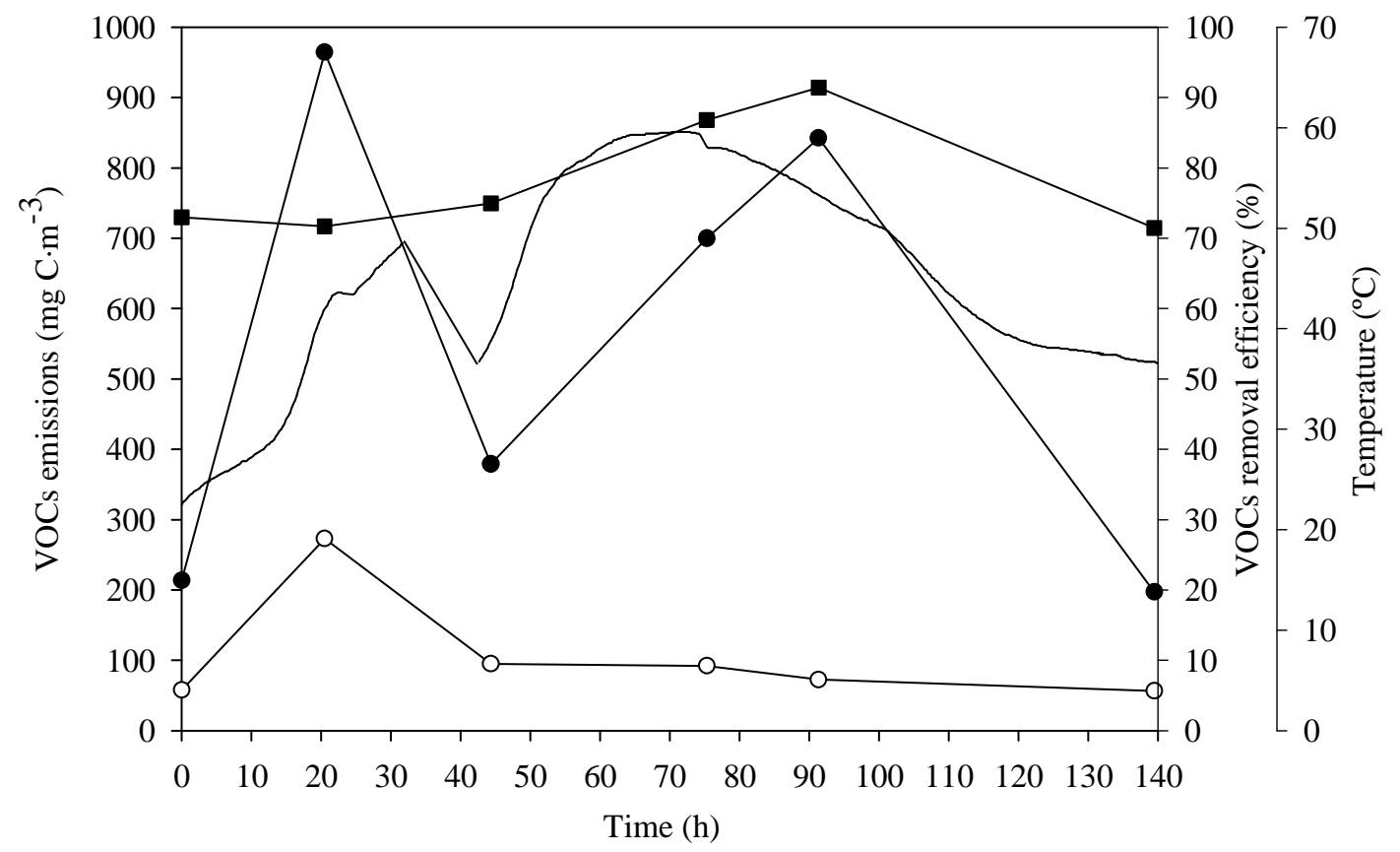


Figure 5: Pagans et al.

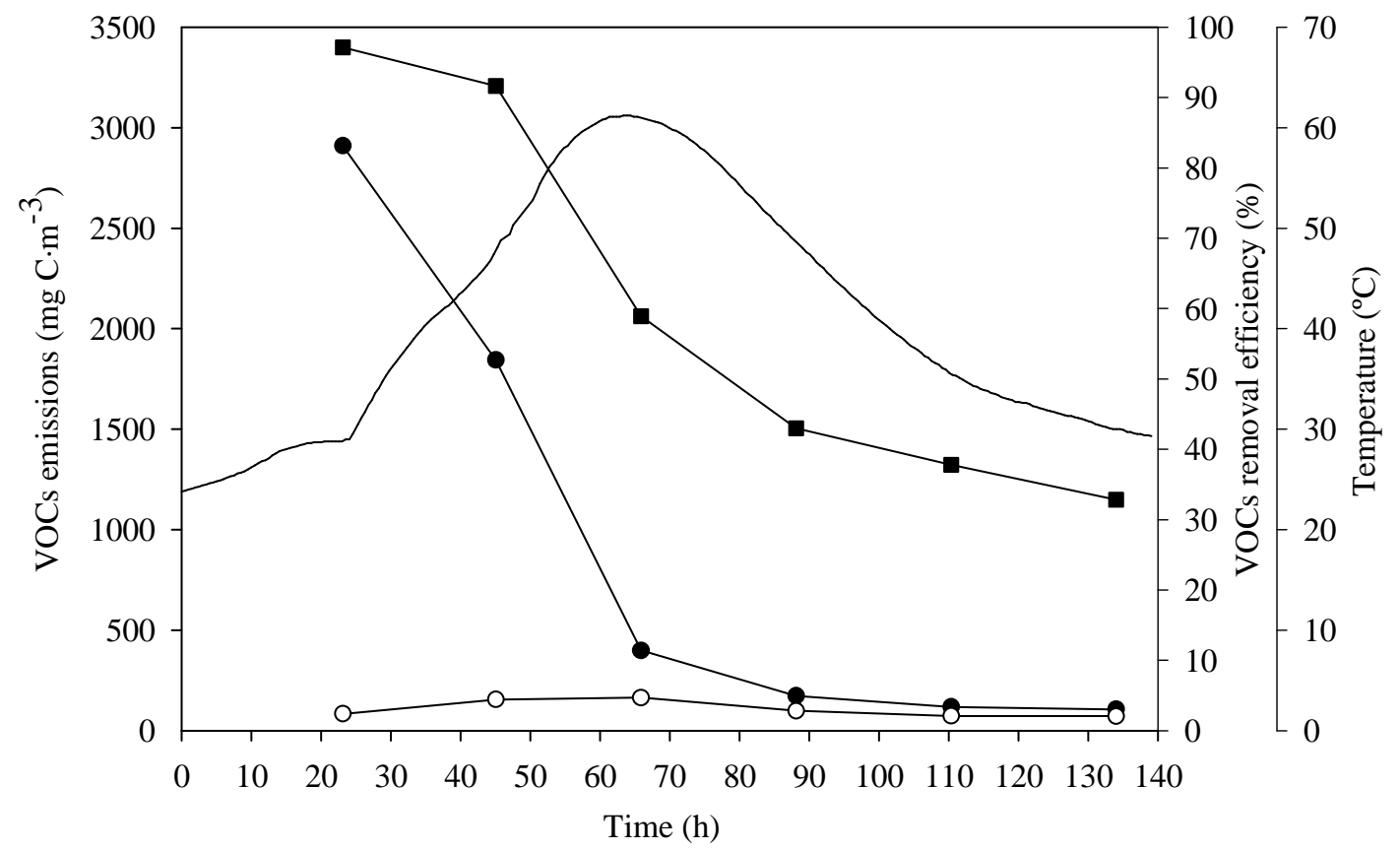


Figure 6: Pagans et al.

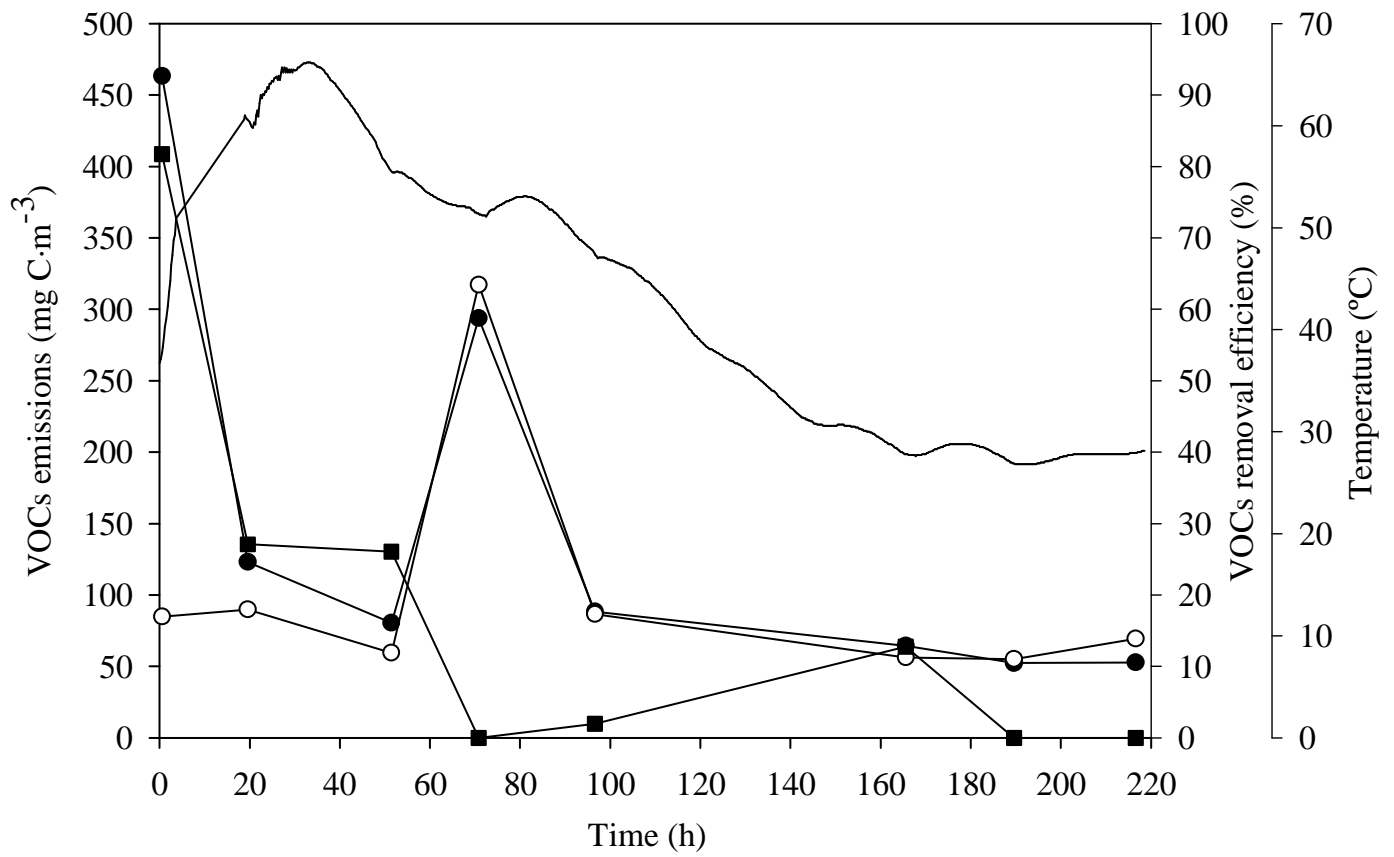


Figure 7: Pagans et al.

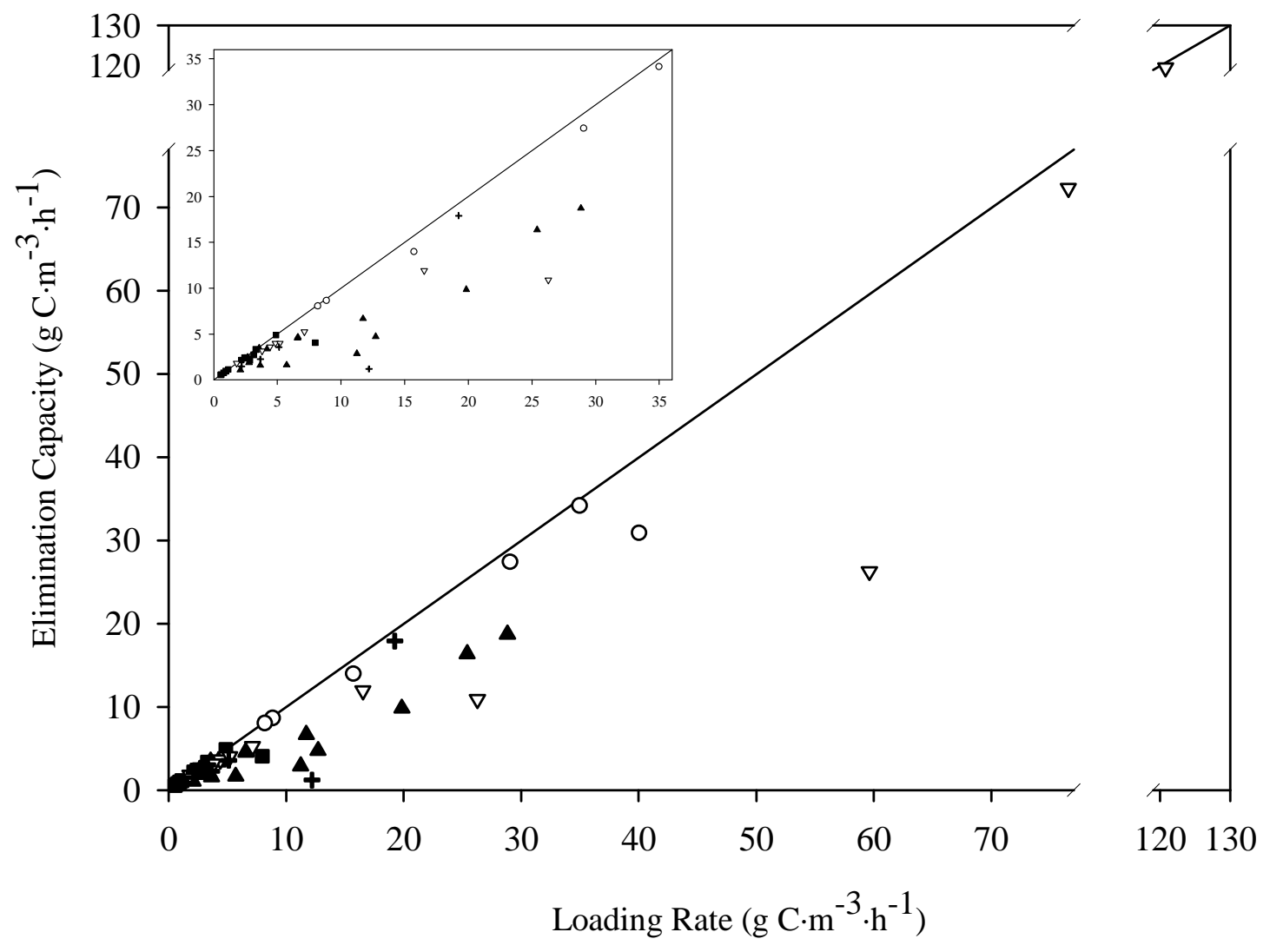

